\title{
Development of the Quantitative Reasoning Items on the National Survey of Student Engagement
}

Amber D. Dumford

Indiana University - Bloomington, adlamber@indiana.edu

Louis M. Rocconi

Indiana University Bloomington, Irocconi@utk.edu

Follow this and additional works at: https://digitalcommons.usf.edu/numeracy

Part of the Higher Education Commons

\section{Recommended Citation}

Dumford, Amber D., and Louis M. Rocconi. "Development of the Quantitative Reasoning Items on the National Survey of Student Engagement." Numeracy 8, Iss. 1 (2015): Article 5. DOI: http://dx.doi.org/ 10.5038/1936-4660.8.1.5 


\title{
Development of the Quantitative Reasoning Items on the National Survey of Student Engagement
}

\begin{abstract}
As society's needs for quantitative skills become more prevalent, college graduates require quantitative skills regardless of their career choices. Therefore, it is important that institutions assess students' engagement in quantitative activities during college. This study chronicles the process taken by the National Survey of Student Engagement (NSSE) to develop items that measure students' participation in quantitative reasoning (QR) activities. On the whole, findings across the quantitative and qualitative analyses suggest good overall properties for the developed QR items. The items show great promise to explore and evaluate the frequency with which college students participate in QR-related activities. Each year, hundreds of institutions across the United States and Canada participate in NSSE, and, with the addition of these new items on the core survey, every participating institution will have information on this topic. Our hope is that these items will spur conversations on campuses about students' use of quantitative reasoning activities.
\end{abstract}

\section{Keywords}

quantitative reasoning, quantitative literacy, student engagement, survey development

\section{Creative Commons License}

\section{c) (i) (8)}

This work is licensed under a Creative Commons Attribution-Noncommercial 4.0 License

\section{Cover Page Footnote}

Amber D. Dumford is an assistant research scientist at the Indiana University Center for Postsecondary Research. In her role as a research analyst, Amber provides analytic support to several large survey research projects, including the Strategic National Arts Alumni Project and the National Survey of Student Engagement. Her research interests include gender issues in higher education, methodological issues in survey research, arts education, engineering education, creativity, and quantitative reasoning.

Louis M. Rocconi is an assistant research scientist at the Indiana University Center for Postsecondary Research. He provides analytic support for the National Survey of Student Engagement and the Law School Survey of Student Engagement. His research interests include methodological issues in educational research, student growth and development in college, and students' use of quantitative reasoning activities. 


\section{Introduction}

Society's needs for quantitative skills become more prevalent with each passing day (Steen 2001; Madison and Steen 2008; Madison 2009; Dingman and Madison 2010). College graduates, regardless of their career choices, require quantitative skills (Rivera-Batiz 1992; Steen 2001; Dingman and Madison 2011). Not only are quantitative skills needed for the workplace; they are needed to be a productive citizen in our democratic society (Steen 2001; Shavelson 2008). Quoting Mathematics and Democracy (Steen 2001: 2):

Quantitative literacy empowers people by giving them tools to think for themselves, to ask intelligent questions of experts, and to confront authority confidently. These are skills required to thrive in the modern world.

The concept of quantitative literacy is more than simply the ability to compute and solve mathematical problems. Quantitative literacy requires a deeper understanding of quantitative information and includes the ability to use numerical, statistical, and graphical information in everyday life, as well as in the workplace (Steen 1997, 2001; Wilkins 2000, 2010). Both Wilkins (2000) and Steen (1997) describe a quantitatively literate person as one who has knowledge of mathematical content and can use that knowledge to help them understand and deal with everyday situations that include mathematical information. Having these quantitative skills is at the core of being a quantitatively literature person.

Noting the importance of quantitative literacy, what is the current state of quantitative literacy in the United States? The Mathematical Association of America (1994), the National Research Council (1989), the National Council of Teachers of Mathematics $(1989,2000)$, the Association of American Colleges and Universities (AAC\&U 2007, 2009), and the National Committee on Excellence in Education (1983) have also asked this question. Two organizations have tried to answer it by studying literacy levels of adults in the United States and abroad. Over a decade ago, the 2003 National Assessment of Adult Literacy (NAAL) found no significant gains between 1992 and 2003 in quantitative literacy at any education level (Kutner et al. 2007); more importantly, only about one-third of college graduates demonstrated proficiency in quantitative literacy. A more-recent assessment of adult literacy from the Organisation for Economic Co-operation and Development (OECD 2013) found that U.S. adults ranked near the bottom in quantitative literacy compared to other developed nations. Despite this fact, the OECD study also found that American workers reported some of the most frequent use of quantitative reasoning skills on their jobs. Thus, while we Americans ranked among the lowest in quantitative literacy ability, we ranked among the highest in our reported use of quantitative skills in the workplace. The findings from the NAAL and OECD highlight the continued need for colleges and 
universities to focus on developing students' ability to make sense of, effectively use, and be knowledgeable consumers of quantitative information (Taylor 2008; Dingman and Madison 2010, 2011). While a number of colleges and universities have instituted programs designed to ensure that their graduates develop quantitative reasoning skills regardless of major (Gillman 2006; Rocconi et al. 2013), findings from NAAL and OECD suggest an urgent need for colleges and universities to assess the opportunities they provide to students to develop facility with quantitative reasoning in all majors.

This paper will discuss new items that were developed to assess students' use of quantitative reasoning (QR) activities in college. These items have been added to the National Survey of Student Engagement (NSSE) and administered at a wide number of institutions. In this paper, we will detail the multi-year itemdevelopment process and present results from quantitative and qualitative analyses that were used to evaluate the validity and reliability of the newly developed items. The quantitative reasoning items discussed in this paper are not intended to measure students' actual quantitative reasoning abilities. Rather, they represent students' perceptions of how often they have engaged in activities that are thought to develop QR skills.

\section{What is NSSE?}

The National Survey of Student Engagement (NSSE) is an annual survey that is administered to first-year and senior students at four-year colleges and universities across the country. NSSE documents the extent to which students engage in educationally purposeful activities that have been shown to support and promote student success (McCormick et al. 2013). Since NSSE was first administered in 2000, more than one million first-year and senior students at more than 1,500 colleges and universities have responded to the annual survey (NSSE 2013). The survey asks students about various aspects of their undergraduate experience, such as the time and effort they invest in their studies, their interactions with faculty members and students, and other educationally purposeful activities. NSSE does not assess student learning directly; rather, the survey enables institutions to pinpoint areas where they are performing well and identify aspects of the undergraduate experience that could be improved. Administrators, faculty members, researchers, and others use the data collected by NSSE for institutional improvement, accreditation, public reporting, and related purposes.

A multi-year development effort to update the National Survey of Student Engagement began in 2009 and concluded in 2013. In 2013, the revised version of the survey was launched, and it included updates to many items and the addition of several new content areas like quantitative reasoning and effective teaching 
practices. Up to then, the NSSE survey questions (see NSSE before 2013 in Appendix A) did not adequately address the activities that science, technology, engineering, and mathematics (STEM) majors frequently use. Thus, there was a perception that the survey painted arts and humanities respondents more favorably than STEM respondents by not sufficiently including questions that STEM majors would naturally report more frequently. From the beginning of the process, NSSE staff identified quantitative literacy/quantitative reasoning as an untapped content area in need of further investigation and for possible inclusion on the core survey instrument. Given the calls from major higher education associations about the importance of developing QR skills among college students, its centrality to general education outcomes (Schneider 2004; AAC\&U 2007, 2009), and the arguments put forth by members of the QR community (Steen 2001; Madison and Steen 2003), the NSSE staff developed a set of items which explored students use of $\mathrm{QR}$ activities in college.

\section{Development Process}

\section{Experimental Items in 2010}

Each year NSSE appends experimental sets of items to the end of the survey either to test possible new survey items or to ask questions about specific areas not on the survey. In 2010, a set of items that focused on students' use of QR activities was appended to NSSE. These items had been developed by NSSE staff from an extensive review of the QL/QR literature which has been briefly discussed earlier in this article (also see Rocconi et al. 2013). While reviewing the literature, NSSE staff realized that it would be difficult to write survey questions that directly measure the actual skills identified in the QR literature and those questions would not fit with the mission of a survey to assess student engagement. NSSE staff recognized that QR abilities and quantitative literacy would be better measured by using formal tests (e.g., CLA). Thus, NSSE would be most appropriate for investigating how often students report participating in QR-related activities. Additionally, staff focused on developing items that students in all majors could report doing.

From this process, seven items, which focused on student behaviors and use of numerical, graphical, and statistical information (see Experimental Set, 2010 in Appendix A), were initially developed by NSSE staff. All psychometric evidence suggested several combinations of the seven items could in theory be used to assess students' use of QR activities well. Knowing there would be limited space on the NSSE instrument, NSSE staff selected four out of the seven items to be administered on the first pilot of the updated survey in 2011. NSSE staff ultimately made the decision based on the following criteria: face validity; the extent to which the content fit well within the larger survey of student 
engagement measures; importance to all college students; and actionable data for institutions interested in making campus improvements. NSSE staff, with input from experts in the field, believed the four items finally selected for additional testing in 2011 well represented the breadth of QR tasks performed in college.

\section{First Pilot in 2011: Quantitative Analyses and Results}

In the spring semester of 2011, an updated version of the NSSE survey was piloted at 19 four-year institutions across the United States. Over 17,000 first-year and senior students responded to the first pilot. This pilot administration included four questions related to students' use of QR activities (see NSSE Pilot 2011 in Appendix A). In order to assess the validity and reliability of the survey, various quantitative and qualitative analyses were conducted on all the items on the first pilot, including the QR items. Herein, we will discuss the findings that related to the evolution of the QR items. Preliminary analyses included descriptive statistics to investigate if there were any odd anomalies in the data such as distributions with excessive skewness or kurtosis. None were found for the QR items.

EFA. Using half of the sample (split by stratified random sampling within class), an exploratory factor analysis (EFA) -- utilizing a principal component extraction method -- was done for all items on the core pilot survey (the NSSE survey administration consists of a core survey, which is administered to all firstyear and senior students. In addition, institutions can select supplementary sets of questions, known as modules, which come after the core survey and focus on specific issues, such as advising, technology, or diversity). A direct oblimin (oblique) rotation was used to allow for correlation between factors, and all components with an eigenvalue greater than 1 were extracted. The Kaiser-MeyerOlkin measure of sampling adequacy was .93, and Bartlett's test of sphericity was significant $\left(\chi^{2}(2485)=143940, p<.001\right)$. Sixteen components were extracted which explained $60.3 \%$ of the variance. The four QR items had factor loadings ranging from .816 to .886 , and the items did not have any high cross-loadings (loadings greater than .40 ) with any of the other factors.

CFA. Using the second half of the sample, confirmatory factor analyses (CFA) were done for the factors suggested by the EFA. For QR, this meant a onefactor model with the four QR items. To ensure that the QR factor was appropriate for students throughout their college careers, separate analyses were completed for first-years and then again for seniors. To determine model fit, five different indices were considered: CMIN/DF (chi-square divided by degrees of freedom), GFI (goodness of fit index), CFI (comparative fit index), RMSEA (root mean square error of approximation), and PCLOSE (p-value for test of close fit) as recommended by $\mathrm{Hu}$ and Bentler (1999). Good model fit criteria for CMIN/DF is a value of 5 or less; however, this statistic is very sensitive to sample size and likely to be inflated with large samples. For the other indices, strong model fit is 
reflected by GFI and CFI greater than or equal to .95, RMSEA less than .06, and PCLOSE greater than .05 ( $\mathrm{Hu}$ and Bentler 1999). The CFA for the QR items indicated overall good model fit (for exact values see Table 1). The standardized regression weights showed good strength of factor loadings, ranging from .680 to .876 for first-years and from .736 to .905 for seniors. Overall, the fit indices and regression weights suggest an adequate scale.

Table 1

Confirmatory factor analysis: Model-fit results

\begin{tabular}{lrrrrl}
\hline & CMIN/DF & GFI & CFI & RMSEA & PCLOSE \\
\hline $\mathbf{2 0 1 1}$ & & & & & \\
First-year & 8.645 & .998 & .999 & .052 & .380 \\
Seniors & 53.525 & .995 & .999 & .064 & .170 \\
\hline $\mathbf{2 0 1 2}$ & & & & & \\
First-year & 8.393 & .997 & .997 & .030 & 1.000 \\
Seniors & 25.020 & .995 & .994 & .042 & .993 \\
\hline $\mathbf{2 0 1 3}$ & & & & & \\
First-year & 92.424 & .979 & .976 & .042 & 1.000 \\
Seniors & 187.862 & .971 & .972 & .048 & 1.000 \\
\hline
\end{tabular}

Note: Adequate model fit is reflected by GFI $\geq .95, \mathrm{CFI} \geq .95$, RMSEA < .06, and PCLOSE > .05 (Hu and Bentler 1999

Reliability. The Cronbach's alpha for the QR items was .881 for firstyears and .894 for seniors. Inter-item correlations ranged between .584 and .763 for first-years and .630 and .801 for seniors. The average inter-item correlations were .65 for first-years and .68 for seniors suggesting moderate correlation for the items in the scale. The items "Analyzed others' conclusions by using numbers, graphs, or statistics" and "Explained in writing the meaning of numbers, graphs, and statistics" were the two items with the strongest pairwise correlation (Firstyear (FY): $r=.763$; Senior (SR): $r=.801$ ). The high correlations between these two items suggest that the two items are redundant. Although the content of the items seems to suggest otherwise, these items were continually monitored for high collinearity in subsequent analyses.

\section{First Pilot in 2011: Qualitative Analyses and Results}

In addition to the quantitative analyses done on the 2011 pilot, cognitive interviews and focus groups with students were conducted. These data collection procedures helped us address the broadest definition of validity, whether the items produce results consistent with their intent. The three main goals of the cognitive interviews and focus groups were (1) to explore the thought processes that students use to answer the survey items, (2) to obtain information about the meaning students make of the survey items, and (3) to identify item or terms that were not well understood or that could lead to survey response error (Collins 
2003; Drennan 2003; Ouimet et al. 2004; Willis 2005). Over the course of the three-year NSSE update process, we conducted cognitive interviews and focus groups with around 180 students at 12 different four-year colleges and universities in the Midwest. Campuses that were selected represented a range of institutional characteristics, varying in enrollment size, sector (public or private), religious affiliation, and Carnegie classification.

One of the goals of the cognitive interview process was to identify items or terms that were not well understood. Findings from the first pilot revealed three main aspects of the QR items that could be improved. First, respondents thought the phrase "numbers, graphs, or statistics" was redundant and asked why that phrase was repeated in each question. Second, respondents had difficulties understanding the terms "contemporary" and "historical" in "Used numbers, graphs, or statistics to help analyze a contemporary or historical issue (poverty, climate change, etc.)." Students did not understand the meaning of the terms and some stated that when they saw the word "historical" they immediately thought of history class. Generally, students thought the examples in the parenthetical were helpful and some respondents suggested including additional examples. Finally, respondents questioned who "others" was referring to in "Analyzed others' conclusions by using numbers, graphs, or statistics." Some were interpreting it as evaluating other students' work, and some students were interpreting it as evaluating the work of experts, researchers, or the professor. Additionally, another set of students thought of both groups when responding to the question.

\section{First Pilot in 2011: Decisions}

Given the findings from the cognitive interviews, along with results from the quantitative analyses, several edits were made to the QR items for the second pilot administration. First, a decision was made to move the question that asks students how often they explained numerical information in their writing to a new topical module (as previously mentioned, modules are sets of supplementary questions that an institution can elect to use in addition to the core survey) that was being developed around students' experiences with writing. This item was shown to be highly correlated with another QR item (analyzing others' conclusions), and NSSE staff decided it fit better with the content of the new module. A decision was also made to replace the phrase "numbers, graphs or statistics" in every question with "numerical information." Also, given the issues students discussed with the terms contemporary and historical, the decision was made to revise that question so that more students could accurately respond to the question. "Contemporary or historical issue" was replaced with "real-world problem or issue" and additional examples were included in the parenthetical. Finally, due to the interpretations in the cognitive interviews, "Analyzed others' conclusions 
using numbers, graphs, or statistics" was changed to "Evaluated what others have concluded from numerical information."

\section{Second Pilot in 2012: Quantitative Analyses and Results}

The same analyses as those conducted for the 2011 pilot were done to test the items on the NSSE 2012 pilot. The second pilot included almost 46,000 first-year and senior students from 57 institutions. These institutions represented a variety of four-year institutions from various Carnegie classifications, enrollment sizes, and regions of U.S. This pilot administration included three QR items on the core pilot survey (see NSSE Pilot 2012 in Appendix A). Again, no anomalies were found with the item descriptives.

EFA. The EFA for the second pilot included all items on the core survey and mirrored that of the first pilot except that separate principal component analyses were conducted for first-year and senior students. The Kaiser-Meyer-Olkin measure of sampling adequacy was .95 for both first-year and senior students, and Bartlett's test of sphericity was significant for both first-year $\left(\chi^{2}(3321)=\right.$ $168,211, \mathrm{p}<.001)$ and senior students $\left(\chi^{2}(3321)=273,504, \mathrm{p}<.001\right)$. Fifteen components were extracted which explained $58.6 \%$ of the variance for first-year students and $60.3 \%$ of the variance for seniors. The three QR items had factor loadings ranging from .817 to .825 for first-year students and .804 to .856 for seniors. Additionally, the QR items did not have any high cross-loadings (loadings greater than .40) with any of the other factors.

CFA. With the 2012 pilot, thematic areas were developed and QR was placed in the academic challenge area. All the same procedures were used as in 2011, but the newly developed thematic areas were used to decide how to structure the models. For more information about all the factors on the NSSE survey, as well as the thematic areas, please visit the NSSE website. ${ }^{1}$ There was overall very good model fit. All of the model fit indices, with the exception of CMIN/DF that is highly sensitive to the large sample size, met the criteria (for exact values see Table 1). The standardized regression weights showed good strength of factor loadings for QR, ranging from .74 to .85 for first-years, and from .77 to .88 for seniors. Overall, the fit indices, factor correlations, and regression weights suggest a good scale for QR.

Reliability. The Cronbach's alpha for the QR scale, created from the three items, was .848 for first-years and .865 for seniors. Removing any single item from the scale would lower the Cronbach's alpha. Inter-item correlations ranged from .606 to .713 for first-year students and .633 and .723 for seniors.

\footnotetext{
${ }^{1}$ http://nsse.iub.edu/html/engagement_indicators.cfm "NSSE, National Survey of Student Engagement, NSSE Findings, Engagement Indicators" (accessed Oct. 28, 2014)
} 


\section{Second Pilot in 2012: Qualitative Analyses and Results}

Cognitive interviews and focus groups were also conducted using the items in the second pilot in 2012. Overall, findings revealed that respondents were generally able to give examples of when they had used numerical information to reach a conclusion, to examine a real-world issue, and to evaluate others' conclusions. Students thought of a variety of courses when answering these questions such as architecture, biology, economics, engineering, marketing, nursing, political science, and psychology. However, non-STEM majors tended to have more difficulty in formulating examples and found it more difficult to think beyond mathematics courses. For instance, "Honestly I haven't had a math class yet." (a first-year musical theater major) and "I'm an English major. I don't deal with numbers." (a senior English major) were the type of responses occasionally given by students in non-STEM type fields.

Given the difficulty for some students to think beyond mathematics and science courses, we suspect that there could be a problem with underestimating for these items. There were instances where students indicated they would have answered "never" because they originally only thought of their math or science classes, but when promoted to think about other classes, they were able to come up with examples or situations of when they had done this. For example, a senior architecture/urban planning student originally responded "never" to "Used numerical information to examine a real-world problem or issue" but when the interviewer recalled a previous discussion about designing floor plans, the respondent stated that he did not originally think of architecture problems when answering this question. The respondent then gave the following example: "[My class] went to a site; it was at street level and there was a path to the White River, and we had to connect the street to the bike path, and we had to create a slope that wouldn't be steep but would go through the site."

The other two goals of the cognitive interview process were to examine respondents' thought process while they answered the questions and obtain the meaning respondents make of the survey items. To this end, we asked respondents to share examples of what they were thinking while they answered these questions. Below are examples students gave for each of the three QR items:

\section{Reached conclusions based on your own analysis of numerical information}

- "When in business you have to analyze numbers and explain them." Sophomore Business major

- "For clinical we look at labs, we use the numbers to understand how the patient is doing." Senior Nursing major 
Used numerical information to examine a real-world problem or issue

- "In a couple of my classes we take information, like if it was for water quality or something like that, we would take the data and make an Excel spreadsheet and look at it and decided how that applied to a problem, so if it was pollution in a stream, what streams are affected, what can we do to prevent it, where's it coming from, those kinds of issues." Senior Natural Science major

- 'In the classes I'm taking we learn a lot about helping people. Learning about triglycerides and blood lipid levels and how these related to realworld problems like obesity, diabetes, metabolic syndrome, heart disease." Senior Kinesiology major

- "The only time I use numbers or graphs... would be like angles and cuts. I'm in a wood working class... and sometimes you need an exact number or angle." Senior Arts/Ceramics major

\section{Evaluated what others have concluded from numerical information}

- "You should always, when you see someone drawing a conclusion based on a statistics, you should try to see how they arrived at that so it's not manipulated to what they want." Senior English major

- "My courses always emphasize not taking things at face value, you have to think about it and look at every side before making a conclusion about what it says, especially with numbers and graphs, it's saying this but what is it really saying?" Senior Kinesiology major

\section{Second Pilot in 2012: Decisions}

Changes between the 2012 pilot and the final item set on NSSE included only a change in the parenthetical after real-world problem or issue, where "disease prevention" was changed to "public health." This change was made in response to suggestions from the cognitive interviews. No other changes seemed to be needed, as the analyses showed the items to be working well on all measures. The QR items were ready to be launched on the updated NSSE in 2013.

\section{NSSE 2013}

In 2013, the updated NSSE survey was launched. For participating institutions in the U.S. nearly 336,000 first-year and senior students from 586 institutions responded. The same quantitative analyses that were done on the pilots were also conducted on the data from the NSSE 2013 administration. Descriptive statistics for the three items are in Table 2. The most common response to the three items 
was "sometimes" with over $60 \%$ of students responding "sometimes" or "often" to all three items. Again, no anomalies were found with the item descriptives for the final three QR items (see NSSE 2013 in Appendix A).

Table 2

Frequencies and descriptive statistics for the Quantitative Reasoning items on the 2013 National Survey of Student Engagement

\begin{tabular}{|c|c|c|c|c|c|c|c|}
\hline & & Response \% & & Mean & S.D. & Skewness & Kurtosis \\
\hline \multirow{8}{*}{$\begin{array}{l}\text { Reached conclusions based on your } \\
\text { own analysis of numerical } \\
\text { information (numbers, graphs, } \\
\text { statistics, etc.) }\end{array}$} & \multirow{4}{*}{ First-year } & Never & 14 & \multirow{4}{*}{2.55} & \multirow{4}{*}{.94} & \multirow{4}{*}{-.01} & \multirow{4}{*}{-.89} \\
\hline & & Sometimes & 35 & & & & \\
\hline & & Often & 34 & & & & \\
\hline & & Very often & 18 & & & & \\
\hline & \multirow{4}{*}{ Senior } & Never & 13 & \multirow{4}{*}{2.63} & \multirow{4}{*}{.96} & \multirow{4}{*}{-.07} & \multirow{4}{*}{-.98} \\
\hline & & Sometimes & 33 & & & & \\
\hline & & Often & 32 & & & & \\
\hline & & Very often & 22 & & & & \\
\hline \multirow{8}{*}{$\begin{array}{l}\text { Used numerical information to } \\
\text { examine a real-world problem or } \\
\text { issue (unemployment, climate } \\
\text { change, public health, etc.) }\end{array}$} & \multirow{4}{*}{ First-year } & Never & 22 & \multirow{4}{*}{2.28} & \multirow{4}{*}{.94} & \multirow{4}{*}{.28} & \multirow{4}{*}{-.81} \\
\hline & & Sometimes & 40 & & & & \\
\hline & & Often & 26 & & & & \\
\hline & & Very often & 12 & & & & \\
\hline & \multirow{4}{*}{ Senior } & Never & 19 & \multirow{4}{*}{2.42} & \multirow{4}{*}{.98} & \multirow{4}{*}{.16} & \multirow{4}{*}{-.98} \\
\hline & & Sometimes & 37 & & & & \\
\hline & & Often & 27 & & & & \\
\hline & & Very often & 17 & & & & \\
\hline \multirow{8}{*}{$\begin{array}{l}\text { Evaluated what others have } \\
\text { concluded from numerical } \\
\text { information }\end{array}$} & \multirow{4}{*}{ First-year } & Never & 22 & \multirow{4}{*}{2.26} & \multirow{4}{*}{.92} & \multirow{4}{*}{.30} & \multirow{4}{*}{-.73} \\
\hline & & Sometimes & 41 & & & & \\
\hline & & Often & 26 & & & & \\
\hline & & Very often & 11 & & & & \\
\hline & \multirow{4}{*}{ Senior } & Never & 18 & \multirow{4}{*}{2.41} & \multirow{4}{*}{.96} & \multirow{4}{*}{.17} & \multirow{4}{*}{-.90} \\
\hline & & Sometimes & 38 & & & & \\
\hline & & Often & 28 & & & & \\
\hline & & Very often & 15 & & & & \\
\hline
\end{tabular}

EFA. Because of changes that were made to other questions on the NSSE core survey, EFA analyses were done once again, but the same steps and parameters from the second pilot were used for the NSSE 2013 administration. The Kaiser-Meyer-Olkin measure of sampling adequacy was .94 for both firstyear and senior students, and Bartlett's test of sphericity was significant for both first-year $\left(\chi^{2}(1653)=1068905, \mathrm{p}<.001\right)$ and senior students $\left(\chi^{2}(1653)=\right.$ $1643150, \mathrm{p}<.001)$. Twelve components were extracted for first-year students which explained $65.4 \%$ of the variance and thirteen components were extracted for senior students which explained $68.6 \%$ of the variance. The three QR items had factor loadings ranging from .868 to .909 for first-year students and .905 to .918 for seniors. Additionally, the QR items did not have any high cross-loadings (loadings greater than .40) with any of the other factors. For full results on the 
EFA and all other analyses, please visit the psychometric portfolio on the NSSE website. $^{2}$

CFA. The model used mirrored that of the second pilot. Again, there was overall very good model fit. All of the model fit indices met the criteria, except CMIN/DF, which is so sensitive to our large sample size (for exact values see Table 1). The standardized regression weights showed good strength of factor loadings for QR, ranging from .74 to .86 for first-years and from .78 to .88 for seniors. Overall, the fit indices, factor correlations, and regression weights suggest a continued good scale for QR.

Reliability. In general, this scale was very good in terms of reliability. The Cronbach's alpha for the QR items was .855 for first-years and .874 for seniors. Removing any single item from the scale will lower the Cronbach's alpha. Interitem correlations ranged from .625 to .731 for first-year students and .660 and .747 for seniors.

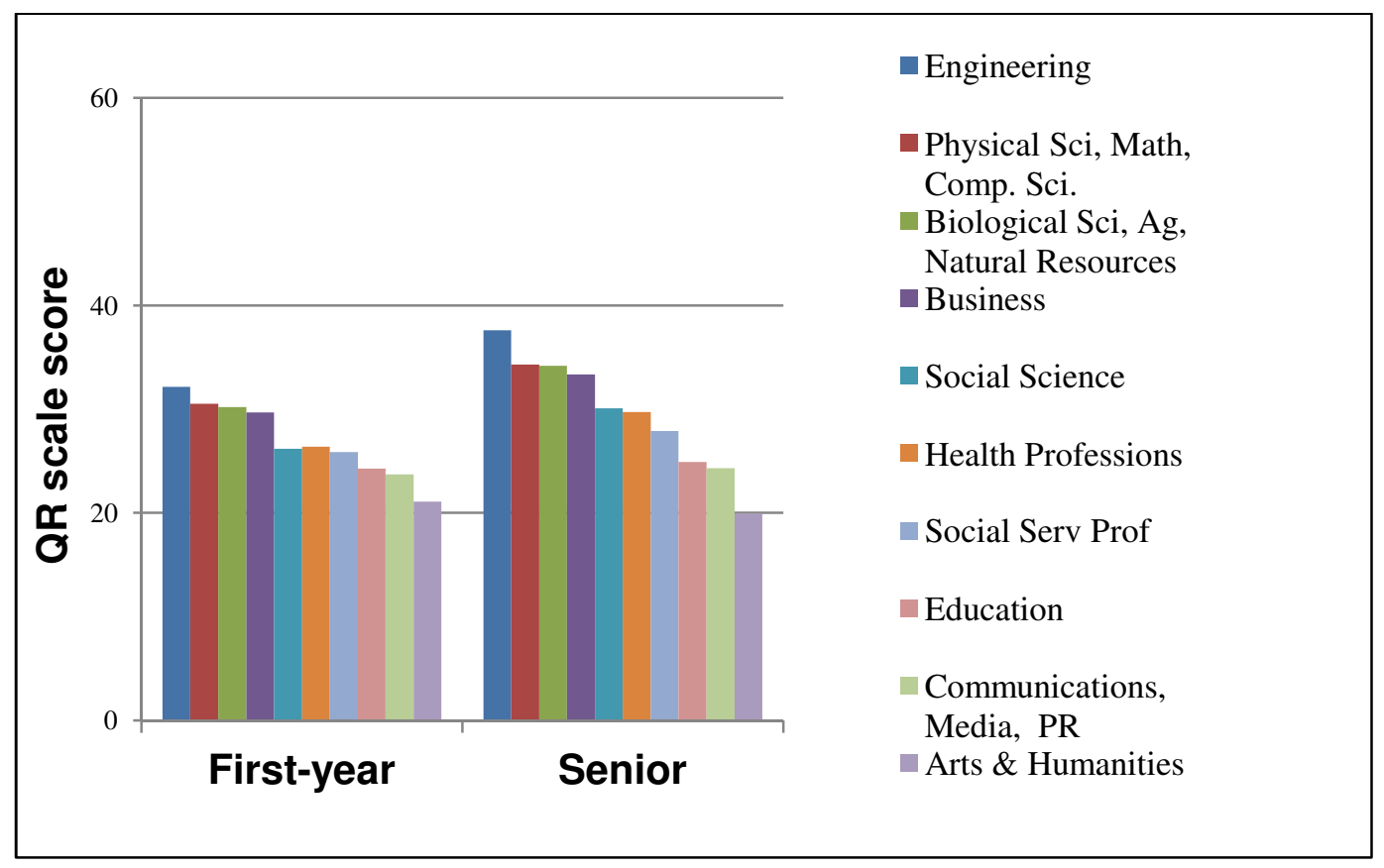

Figure 1. Student use of QR Activities by Major Field. All engagement indicators on NSSE are expressed on a 60-point scale. For information about computing engagement indicator scores see http://nsse.iub.edu/html/engagement_indicators.cfm

\footnotetext{
${ }^{2}$ http://nsse.iub.edu/html/psychometric_portfolio.cfm "NSSE, National Survey of Student Engagement, NSSE Findings, Psychometric Portfolio" (accessed Oct. 28, 2014).
} 
Known-Groups Validity. These analyses looked at group differences by gender, citizenship, and discipline, which have been shown to differ in their scores on assessments of QR (Kutner et al. 2007; OECD 2013). Gender and citizenship were examined using t-tests, and discipline differences were explored using an ANOVA. Overall, male students (compared to female students) were more likely to participate in activities related to quantitative reasoning $(\mathrm{p}<.001$; First-year (FY) Cohen's $d$ effect size $=.287$; Senior $(\mathrm{SR})$ Cohen's $d$ effect size $=$ .282). Similarly international students outscored their domestic counterparts $(p<$ .001 ; FY Cohen's $d$ effect size $=.253$; SR Cohen's $d$ effect size $=.259$ ). Differences were also found by discipline. Not surprisingly those in STEM fields spent more time participating in quantitative reasoning activities their non-STEM counterparts (see Figure 1).

\section{Conclusions}

On the whole, findings across the quantitative and qualitative analyses suggest good overall properties for the QR items. Because of these good properties, the QR items were also adapted for use on NSSE's companion surveys: BCSSE (see Beginning College Survey of Student Engagement 2013 in Appendix A) and FSSE (see Faculty Survey of Student Engagement 2013 in Appendix A).

These items show great promise to explore and assess the frequency with which college students participate in QR-related activities. Each year hundreds of institutions across the United States and Canada participate in the National Survey of Student Engagement, and, with the addition of these new items on the core survey, every participating institution will be collecting data on how often their students are participating in QR activities. These items can give administrators, faculty, and staff insight into disciplines and programs where students are participating in QR activities. Hopefully, these items will spur conversations on campus around $\mathrm{QR}$ and inspire institutions to begin discussions about targeting interventions geared towards students with the least exposure to quantitative activities. Indeed, a recent finding from Rocconi et al. (2013) demonstrated that institutional policies can have a positive influence on students' use of QR activities, especially for students in non-STEM-related fields who are most at risk for not developing these important skills. However, more research is needed to fully explore the effectiveness of QR policies, courses, programs, and centers. These new NSSE items provide institutions a tool to assess the opportunities they provide students in all majors to develop facility with QR.

For those institutions that have already implemented QR policies, courses, programs, or learning centers, NSSE results will enable these institutions to compare their students' use of QR activities to students at other institutions. Not only will these items be beneficial for institutional users, but the widespread 
collection of students' use of QR activities in college will aid administrators, faculty, and researchers in exploring the relationship that participating in $\mathrm{QR}$ activities has with other important postsecondary outcomes such as GPA, critical thinking skills, graduation rates, and employment. Additionally, more research is needed to investigate the link between involvement in QR activities and actual QR abilities. This could be done at the institution level by linking NSSE results with actual QR test scores.

With the growing importance of QR skills in the workplace and in everyday life, it is essential that all college students develop the ability to effectively use and understand quantitative information. Increasing students' exposure to QR activities is a necessary component in achieving this goal. Hopefully the addition of these quantitative reasoning items on the National Survey of Student Engagement will spur further discussions on college students' development of quantitative skills.

\section{Acknowledgments}

The authors would like to thank their fellow National Survey of Student Engagement staff. This work would not be possible without the collaborative effort of all of the employees at the Indiana University Center for Postsecondary Research.

\section{References}

AAC\&U. See Association of American Colleges and Universities.

Association of American Colleges and Universities. 2007. College learning for the new global century: A report from the National Leadership Council for Liberal Education and America's Promise.

http://www.aacu.org/leap/documents/GlobalCentury_final.pdf (accessed April 10, 2012).

- 2009. Quantitative literacy VALUE rubric. http://www.aacu.org/value/rubrics/quantitative-literacy (accessed April 10, 2012).

Collins, D. 2003. Pretesting survey instruments: An overview of cognitive methods. Quality of Life Research 12: 229-238. http://dx.doi.org/10.1023/A:1023254226592

Dingman, S. W., and B. L. Madison. 2010. Quantitative reasoning in the contemporary world, 1: The course and its challenges. Numeracy 3(2): Article 4. http://dx.doi.org/10.5038/1936-4660.3.2.4

- and B. L. Madison. 2011. Twenty-first-century quantitative education: Beyond content. Peer Review 13(3): 15-18.

Drennan, J. 2003. Cognitive interviewing: verbal data in the design and pretesting of questionnaires. Journal of Advanced Nursing 43(1): 57-63. http://dx.doi.org/10.1046/j.1365-2648.2003.02579.x

Gillman, R., ed. 2006. Current practices in quantitative literacy. Washington, D.C.: Mathematics Association of America. 
Hu, L.T., and P. M. Bentler. 1999. Cutoff criteria for fit indices in covariance structure analysis: Conventional versus new alternatives. Structural Equation Modeling 6: 155. http://dx.doi.org/10.1080/10705519909540118

Kunter, M., E. Greenburg, Y. Jin, B. Boyle, Y. Hsu, and E. Dunleavy. 2007. Literacy in everyday life: Results from the 2003 National Assessment of Adult Literacy. Washington, D.C.: U.S. Department of Education, National Center for Educational Statistics (NCES 2007-480).

Madison, B. L. 2009. All the more reason for QR across the curriculum. Numeracy 2 (1): Article 1. http://dx.doi.org/10.5038/1936-4660.2.1.1

- and L. A. Steen, eds. 2008. Calculation vs. context: Quantitative literacy and its implications for teacher education. Racine, WI: Mathematics Association of America.

Mathematical Association of America. 1994. Quantitative reasoning for college students: A complement to the standards. http://www.maa.org/programs/faculty-anddepartments/curriculum-department-guidelines-recommendations/quantitativeliteracy/quantitative-reasoning-college-graduates (accessed October 31, 2014).

McCormick, A. C., J. Kinzie, and R. M. Gonyea. 2013. Student engagement: Bridging research and practice to improve the quality of undergraduate education. In Higher education: Handbook of theory and research, ed. M. B. Paulsen, vol. 28: 47-92. Dordrecht, The Netherlands: Springer.

National Commission on Excellence in Education. 1983. A nation at risk: The imperative for education reform. Washington, DC: U.S. Department of Education.

National Council of Teacher of Mathematics. 1989. Curriculum and evaluation standards for school mathematics. Reston, VA: National Council of Teacher of Mathematics.

- 2000. Principles and standards for school mathematics. Reston, VA: National Council of Teacher of Mathematics.

National Research Council. 1989. Everybody counts: A report to the nation on the future of mathematics education. Washington, DC: National Academies Press.

National Survey of Student Engagement. 2013. NSSE Overview 2013. Bloomington, IN: Center for Postsecondary Research, Indiana University, School of Education. http://nsse.iub.edu/2013 Institutional_Report/pdf/NSSE 2013 Overview.pdf (accessed April 1, 2014).

NSSE. See National Survey of Student Engagement.

OECD. See Organisation for Economic Co-operation and Development.

Organisation for Economic Co-operation and Development . 2013. OECD Skills Outlook 2013: First Results from the Survey of Adult Skills, OECD Publishing. http://dx.doi.org/10.1787/9789264204256-en (accessed March 10, 2014).

Ouimet, J.A., J. C. Bunnage, R. M. Carini, G. D. Kuh, and J. Kennedy. 2004. Using focus groups, expert advice, and cognitive interviews to establish the validity of a college student survey. Research in Higher Education 45(3): 233-250. http://dx.doi.org/10.1023/B:RIHE.0000019588.05470.78

Rivera-Batiz, F. L. 1992. Quantitative literacy and the likelihood of employment among young adults in the United States. The Journal of Human Resources 27(2): 313-328. http://dx.doi.org/10.2307/145737 
Rocconi, L. M., A. D. Lambert, A. C. McCormick, and S. A. Sarraf. 2013. Making college count: An examination of quantitative reasoning activities in higher education, Numeracy 6(2): Article 10. http://dx.doi.org/10.5038/1936-4660.6.2.10

Schneider, C. G. 2004. Setting greater expectations for quantitative learning. Peer Review (Summer 2004): 26-27.

Shavelson, R. J. 2008. Reflections on quantitative reasoning: An assessment perspective. In Madison and Steen 2008, 27-44.

Steen, L. A., ed. 1997. Why numbers count: Quantitative literacy for tomorrow's America. New York: College Entrance Examination Board.

- ed. 2001. Mathematics and democracy: The case for quantitative literacy. Princeton, NY: Woodrow Wilson National Fellowship Foundation.

Taylor, C. 2008. Preparing students for the business of the real (and highly quantitative) world. In Madison and Steen 2008, 109-124.

Wilkins, J. L. M. 2000. Preparing for the $21^{\text {st }}$ century: The status of quantitative literacy in the United States. School Science and Mathematics, 100 (8): 406-418. http://dx.doi.org/10.1111/j.1949-8594.2000.tb17329.x

- 2010. Modeling quantitative literacy. Educational and Psychological Measurement 70(2): 1-24. http://dx.doi.org/10.1177/0013164409344506

Willis, G. 2005. Cognitive interviewing: A tool for improving questionnaire design. Thousand Oaks, CA: Sage Publications.

\section{Appendix A: Questions on the National Survey of Student Engagement related to Quantitative Activities}

\section{National Survey of Student Engagement before 2013:}

Q4. In a typical week, how many homework problem sets do you complete?

a. Number of problem sets that take you more than an hour to complete

b. Number of problems sets that take you less than an hour to complete

\section{Experimental Set, 2010:}

In your experience at your institution during the current school year, about how often have you done each of the following?

[Very often, Often, Sometime, Never]

- Searched for numerical, graphical or statistical information to verify conclusions made without any such evidence

- Interpreted numerical, graphical, or statistical information in order to understand the claims of others

- Evaluated conclusions others have reached based on numerical, graphical, or statistical information 
- Reached conclusions based on your own analysis of numerical, graphical, or statistical information

- Explained in writing the meaning of numerical, graphical, or statistical information

- Used numerical, graphical, or statistical information to help analyze a contemporary or historical issue (e.g., poverty, climate change)

- Collected or produced your own numerical, graphical, or statistical information for an assignment

\section{National Survey of Student Engagement Pilot 2011:}

In your experience at your institution during the current school year, about how often have you done each of the following?

[Very often, Often, Sometime, Never]

- Reached conclusions based on your own analysis of numbers, graphs, or statistics

- Used numbers, graphs, or statistics to help analyze a contemporary or historical issue (poverty, climate change, etc.)

- Explained in writing the meaning of numbers, graphs, or statistics

- Analyzed others' conclusions by using numbers, graphs, or statistics

\section{National Survey of Student Engagement Pilot 2012:}

In your experience at your institution during the current school year, about how often have you done each of the following?

[Very often, Often, Sometime, Never]

- Reached conclusions based on your own analysis of numerical information (numbers, graphs, statistics, etc.)

- Used numerical information to examine a real-world problem or issue (unemployment, climate change, disease prevention, etc.)

- Evaluated what others have concluded from numerical information

\section{National Survey of Student Engagement 2013:}

During the current school year, about how often have you done the following?

[Very often, Often, Sometime, Never]

- Reached conclusions based on your own analysis of numerical information (numbers, graphs, statistics, etc.)

- Used numerical information to examine a real-work problem or issue (unemployment, climate change, public health, etc.)

- Evaluated what others have concluded from numerical information 


\section{Experiences with Writing Topical Module 2013:}

During the current school year, for how many writing assignments have you done the following?

[All writing assignments, Most writing assignments, Some writing assignments, Few writing assignments, No writing assignments]

- Explained in writing the meaning of numerical or statistical data

\section{Beginning College Survey of Student Engagement 2013:}

During your last year of high school, about how often did you do the following? [Very often, Often, Sometimes, Never]

- Reached conclusions based on your own analysis of numerical information (numbers, graphs, statistics, etc.)

- Used numerical information to examine a real-work problem or issue (unemployment, climate change, public health, etc.)

- Evaluated what others have concluded from numerical information

\section{Faculty Survey of Student Engagement 2013:}

In your selected course section, how important is it to you that the typical student does the following?

[Very important, Important, Somewhat important, Not important]

- Reach conclusions based on his or her own analysis of numerical information (numbers, graphs, statistics, etc.)

- Use numerical information to examine a real-work problem or issue (unemployment, climate change, public health, etc.)

- Evaluate what others have concluded from numerical information 